\title{
Possible role of USP26 in patients with severely impaired spermatogenesis
}

\author{
Katrien Stouffs, ${ }^{*}$, Willy Lissens ${ }^{1}$, Herman Tournaye ${ }^{2}$, André Van Steirteghem ${ }^{2}$ and \\ Inge Liebaers ${ }^{1}$
}

${ }^{1}$ Center for Medical Genetics, University Hospital, Dutch-speaking Brussels Free University (Vrije Universiteit Brussel), Laarbeeklaan 101, Brussels, Belgium; ${ }^{2}$ Center for Reproductive Medicine, University Hospital, Dutch-speaking Brussels Free University (Vrije Universiteit Brussel), Laarbeeklaan 101, Brussels, Belgium

The ubiquitin-specific protease 26 (USP26) gene is an X-linked gene specifically expressed in testis tissue. This gene is therefore a potential infertility gene. In order to analyse its possible involvement in spermatogenesis and infertility, 42 patients with Sertoli cell-only syndrome were analysed for mutations in this gene. We found four patients with exactly the same three changes of the nucleotide and therefore also amino acid sequence. These patients showed 370-371 insACA, 494T $>C$ and 1423C $>T$ causing T123-124ins, L165S and H475Y, respectively. These changes were not found in 10 control samples. Furthermore, two polymorphisms were observed which do not alter the amino-acid sequence. A restriction analysis that can make a distinction between a $T$ and a $C$, at position 494, was set up in order to examine more patient and control samples. Another 69 patients with Sertoli cell-only syndrome, 32 patients with maturation arrest and 142 control samples were analysed using this method. None of the control samples or patients with maturation arrest featured the change at position 494. However, four more patients with Sertoli cell-only syndrome were identified with the three alterations. The frequency of alterations in this group is therefore $7.2 \%(8 / 111)$. One of the patients had a deletion of the long arm of the $Y$ chromosome, while another patient had a varicocoele. These results indicate that these alterations might be involved in male infertility or might increase the risk of male infertility.

European Journal of Human Genetics (2005) 13, 336-340. doi:10.1038/sj.ejhg.5201335

Published online 24 November 2004

Keywords: USP26; male infertility; Sertoli cell-only syndrome; X chromosome

\section{Introduction}

Infertility and subfertility affect about $13-18 \%$ of couples seeking to have children. ${ }^{1,2}$ Many causes of male infertility are known, although the group of men whose fertility problems cannot be explained remains large. Genetic

${ }^{*}$ Correspondence: K Stouffs, Center for Medical Genetics, University Hospital, Dutch-speaking Brussels Free University (Vrije Universiteit Brussel), Laarbeeklaan 101, 1090 Brussels, Belgium. Tel: +32 247764 69; Fax: + 32247768 60; E-mail: katrien.stouffs@az.vub.ac.be Received 24 August 2004; revised 6 October 2004; accepted 7 October 2004 factors may explain part of the fertility problems. Mouse studies have shown that $>100$ genes are involved in spermatogenesis. ${ }^{3}$ When knockout mice for these genes were made, defects were often pleiotropic and thus not restricted to an impaired spermatogenesis.

In this study, we have determined the involvement of ubiquitin-specific protease 26 (USP26) in patients with severely impaired spermatogenesis. USP26 was first identified by Wang et al, ${ }^{4}$ who isolated this gene from mouse spermatogonia. A human homologue that shows a testisspecific expression pattern was identified. Since this gene is 
probably involved in the degradation of proteins and since protein production and degradation are indispensable during spermatogenesis, this gene might have a crucial role in spermatogenesis.

USP26 is located on the X chromosome, at Xq26.2. The mRNA sequence of the USP26 gene is $2794 \mathrm{bp}$ long and comprises a single exon. The protein consists of 913 amino acids (Genbank: NM_031907.1).

We have analysed 111 patients with a histology showing Sertoli cell-only syndrome, 32 men diagnosed with a maturation arrest of spermatogenesis and 152 fertile controls for the presence of mutations in USP26.

\section{Materials and methods Patient selection}

In the first part of this study, 10 fertile men (with normal sperm parameters) and 42 patients visiting our centre with a view to ICSI and diagnosed with Sertoli cell-only syndrome (SCOS) were selected. In the testicular tissue of two patients with SCOS, a few spermatozoa were found (and thus referred to as incomplete SCOS or iSCOS), while in the other 40 patients no spermatozoa were detected. The karyotype of these patients was normal and no Yq microdeletions were present.

In the second part of this study, another 69 patients with SCOS were examined of which 21 patients had a few spermatozoa in their testicular tissue (iSCOS). This group of SCOS also included men with Yq microdeletions $(n=10)$, a varicocoele $(n=5)$ or a history of cryptorchidism $(n=9)$. We have also analysed 32 patients with maturation arrest (MA), comprising 13 patients with a deletion of the $\mathrm{Y}$ chromosome. Furthermore, 142 randomly chosen control samples, including 84 fertile (with normal sperm parameters) men and 58 women were analysed.

Histological examination of testicular tissues was performed in the pathology department of our university hospital. When a heterogeneous phenotype was observed, patients were categorised according to the most progressed spermatogenesis found in testicular tissues. When, for example, the histology showed tubuli with SCOS as well as with MA, the histology of this sample was designated as MA. Moreover, if sperm was found at TESE and the histology was SCOS, these samples were referred to as iSCOS.

\section{Polymerase chain reaction (PCR), sequence analysis and restriction analysis}

DNA was isolated from peripheral blood using Qiagen's 'QIamp Blood Maxi Kit Protocol' (Qiagen, The Netherlands). Primers for overlapping fragments were designed to be able to amplify and sequence the entire coding region of the USP26 gene (Table 1) and were synthesised by Eurogentec (Belgium).

PCR reactions were performed in a $100 \mu \mathrm{l}$ mix containing $500 \mathrm{ng}$ of DNA, $1 \times$ PCR Buffer II (Applied Biosystems,
Table 1 Primer sequences

\begin{tabular}{|c|c|c|}
\hline Fragment & Primer & Sequence $\left(5^{\prime}-3^{\prime}\right)$ \\
\hline \multirow[t]{2}{*}{1} & USP26/9 & GTCTTCACAGCTGAACTTGC \\
\hline & USP26/33 & ATCACTTAGCCGAAAAGTGC \\
\hline \multirow[t]{2}{*}{2} & USP $26 / 32$ & GATAGACTGGTGCTGTATTT \\
\hline & USP26/31 & GTGCTAGAAAAGACACTCСС \\
\hline \multirow[t]{2}{*}{3} & USP26/3 & GGATTATCCTCCACAGATGC \\
\hline & USP26/4 & ATAGCTTACACACСТCGAAC \\
\hline \multirow[t]{2}{*}{4} & USP26/29 & СTTACTTGCGGAGAGTTATC \\
\hline & USP26/30 & TCССАСТTTGTGTAACСGTC \\
\hline \multirow[t]{2}{*}{5} & USP26/28 & GGTСТTСТССААGСТСТСАС \\
\hline & USP $26 / 27$ & GCATCGTTCTGTGCATTGCC \\
\hline \multirow[t]{2}{*}{6} & USP26/12 & GGAGATGTTACTCTTGAATC \\
\hline & USP26/17 & СTGAATAGATGAAGGATGTG \\
\hline \multirow[t]{2}{*}{7} & USP26/23 & СTTGTGGTCAGGTTATTCTCC \\
\hline & USP26/24 & TGACTTCСTGGTCATTCTTC \\
\hline \multirow[t]{2}{*}{8} & USP26/25 & TCAGTAGGCTACCTAGAATC \\
\hline & USP26/26 & TCAGАСТССТTАТСТGАТСС \\
\hline \multirow[t]{2}{*}{9} & USP26/22 & TCCAGCTTTGTGGAACTGAC \\
\hline & USP26/1 & GGAAACATCAGTGTATCATGG \\
\hline \multirow[t]{2}{*}{10} & USP26/21 & ACTCAGGAGATCGAGCATTC \\
\hline & USP $26 / 2$ & ССTGCTGAGGGGCTTGTTCAC \\
\hline \multirow[t]{2}{*}{11} & USP26/19 & CAGAATTCCAGAAAGATTCC \\
\hline & USP26/20 & GTCTTCССАAGATGGCTGAC \\
\hline \multirow[t]{2}{*}{12} & USP26/18 & GAGATCATACCTACCGGCTC \\
\hline & USP26/16 & GACCTTTGGTCCTAGACTAA \\
\hline
\end{tabular}

Belgium), $2 \mathrm{mmol} / \mathrm{l}$ of $\mathrm{MgCl}_{2}$ (Applied Biosystems), $0.2 \mathrm{mmol} / \mathrm{l}$ of each dNTP (Amersham Pharmacia Biotech Inc., The Netherlands), $1 \mu \mathrm{mol} / \mathrm{l}$ of each primer and $1.25 \mathrm{U}$ of Taq polymerase (Applied Biosystems). Thermocycling conditions consisted of an initial denaturation of $5 \mathrm{~min}$ at $94^{\circ} \mathrm{C}$, 30 cycles of $1 \mathrm{~min}$ at $94^{\circ} \mathrm{C}, 1 \mathrm{~min}$ at $60^{\circ} \mathrm{C}$, except for fragments $5\left(62^{\circ} \mathrm{C}\right)$ and $6\left(56^{\circ} \mathrm{C}\right)$ and $2 \mathrm{~min}$ at $72^{\circ} \mathrm{C}$ and a final extension of $7 \mathrm{~min}$ at $72^{\circ} \mathrm{C}$. PCR products were analysed on a $2 \%$ agarose gel. After purification, all samples were sequenced with primers used for amplification and run on the ABI310 Genetic Analyser (Applied Biosystems, The Netherlands).

Restriction analysis was performed on the PCR product of fragment 3 with restriction enzyme TaqI and analysed on a $2 \%$ agarose gel.

\section{RNA extraction and RT-PCR}

Fresh testicular tissue was obtained from a patient admitted to hospital for vasectomy repair. This tissue was transferred to cryo-tubes and frozen by plunging it into liquid $\mathrm{N}_{2}$. Ovarian tissue was obtained by autopsy and frozen at $-80^{\circ} \mathrm{C}$. RNA was isolated from these tissues using the Rneasy Mini Kit (Qiagen) in accordance with the instructions issued by the manufacturer. The RNA was incubated with DNAse and purified with the RNA clean-up protocol using the Rneasy Mini Kit. RT-PCR was performed with the First-Strand cDNA synthesis kit (Amersham Pharmacia Biotech Inc.) according to the instructions of the manufacturer. The presence of USP26 RNA was analysed in ovarian and testis tissue using primer pair USP26/3 and 
USP26/4. The presence of good quality RNA in ovarian tissue was confirmed by the amplification of a fragment from DAZLA using primers DAZLAF (GGAGCTATGTTGTACCTCC) and DAZLAR (GTGGGCCATTTCCAGAGGG).

\section{Results}

In the first part of the study, the human USP26 gene was examined by sequencing analysis for the presence of mutations in 42 patients diagnosed with SCOS. The results are summarized in Table 2. The sequence from Genbank (NM_031907.1) was used as the reference sequence and the A of ATG of the initiation signal was numbered +1 . In total, five differences with the published sequence were observed. Four of these are single-nucleotide substitutions, while the fifth change was an insertion of three nucleotides.

Two substitutions, 576G $>\mathrm{A}$ and 2088A $>$ G, do not alter the amino acid sequence: a glutamic acid at position 192 and a proline at position 696, respectively. Two of the four substitutions predict an amino acid alteration: 494T $>\mathrm{C}$ changes a leucine into a serine, while $1423 \mathrm{C}>\mathrm{T}$ substitutes a histidine for a tyrosine. The insert of three nucleotides ACA causes an insert of a threonine. Figure 1 shows the nucleotide changes.

We have found that, in four patients, the three changes 370-371insACA, 494T $>\mathrm{C}$ and $1423 \mathrm{C}>\mathrm{T}$ were present on the same allele. This haplotype was not present in a control group. We have sequenced fragment 3 , containing two of the three changes in 10 men. All samples showed the normal sequence, as published by Wang et al. ${ }^{4}$
The substitution $576 \mathrm{G}>\mathrm{A}$, which is also located in fragment 3 , was found in $50 \%$ of the patients (21/42) and in $50 \%$ of the control group $(5 / 10)$, and is therefore a polymorphism. The substitution $2088 \mathrm{~A}>\mathrm{G}$ was found in one patient $(2.4 \%)$, but since there was no change in the amino acid, this was probably a polymorphism.

In order to analyse a larger group of patients and controls, we set up a restriction reaction that was able to distinguish between a $\mathrm{T}$ or a $\mathrm{C}$ at position 494 . With this method, 101 patients including 69 patients with SCOS and 32 patients with MA were analysed. Four extra patients were found to have the $\mathrm{T}$ to $\mathrm{C}$ substitution. In addition, the presence of the two other changes was confirmed by sequencing the whole USP26 gene in these three patients. All patients had SCOS. Altogether, the frequency of the three changes in the group with SCOS was 7.2\% (Table 3). None of the patients with MA had the T to $\mathrm{C}$ substitution. In total, 84 fertile men and 58 fertile women were analysed (of whom 10 by sequencing and 142 by restriction analysis). None of these control samples showed a $\mathrm{C}$ at position 494. In total, $210 \mathrm{X}$ chromosomes were analysed in a control group and no changes were observed. This difference is statistically significant $\left(\chi^{2}=15.5, P<0.001\right)$.

Of the eight patients with the alterations, one had a varicocoele and another had a deletion of $\mathrm{AZFb}$ and AZFC on the long arm of the $\mathrm{Y}$ chromosome. One patient was having an iSCOS.

The changes in the amino acid sequence have been compared to the amino acid sequence of USP26 from Mus musculus and Rattus norvegicus (Figure 2). The homologous gene in $R$. norvegicus was identified by 'HomoloGene' from Genbank. In humans, two threonine residues are normally

Table 2 Summary of possible mutations and polymorphisms found in 42 patients with SCOS

\begin{tabular}{|c|c|c|c|c|}
\hline Fragment & Nucleotide change & Amino-acid alteration & No. of patients & Frequency (\%) \\
\hline 3 & 370-371 insACA & T123-Q124ins & 4 & 9.5 \\
\hline 3 & $494 \mathrm{~T}>\mathrm{C}$ & L165S & 4 & 9.5 \\
\hline 3 & $576 \mathrm{G}>\mathrm{A}$ & No effect & 21 & 50.0 \\
\hline 7 & $1423 C>T$ & $\mathrm{H} 475 \mathrm{Y}$ & 4 & 9.5 \\
\hline 10 & $2088 A>G$ & No effect & 1 & 2.4 \\
\hline
\end{tabular}

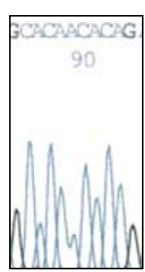

Control

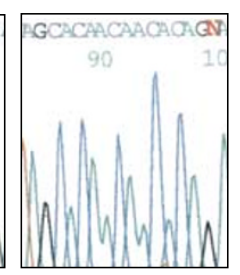

Patient

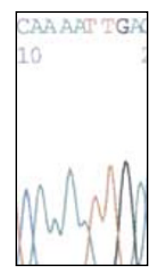

Control

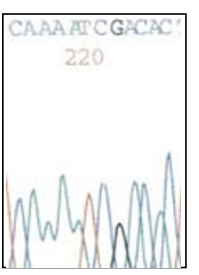

Patient

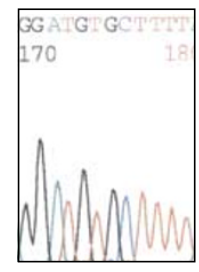

Control

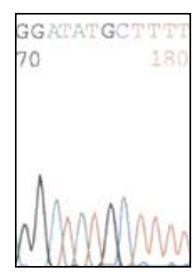

Patient

Ins ACA

$\mathrm{C}>\mathrm{T}$

Figure 1 Normal and altered sequence. Parts of fragment 3, showing the insert of ACA and T>C in a patient and part of fragment 7 , showing $\mathrm{C}>\mathrm{T}$. 
Table 3 Frequency of the three alterations (370-371insACA, 494T $>C$ and $1423 C>T$ ) in the different groups

\begin{tabular}{lccc}
\hline & Total $(n)$ & Alterations $(n)$ & Frequency (\%) \\
\hline SCOS & 111 & 8 & 7.2 \\
MA & 32 & 0 & 0 \\
Controls & 152 & 0 & 0 \\
Control Xs & 210 & 0 & 0 \\
\hline
\end{tabular}

$\mathrm{SCOS}=$ Sertoli cell-only syndrome, $\mathrm{MA}=$ maturation arrest.

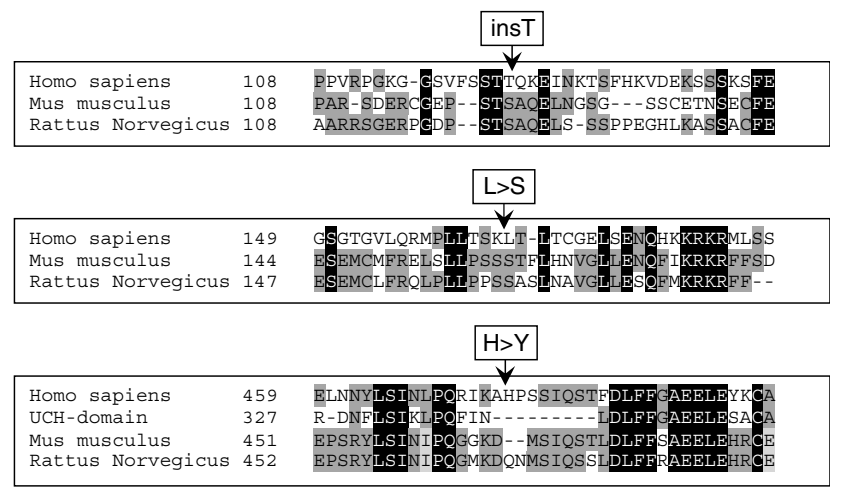

Figure 2 Homology of the USP26 amino acid sequence between humans, mice and rats. Alignment of the Homo Sapiens (NP_114113.1), M. musculus (NP_113565.1) and $R$. Norvegicus (XP_228680.1) polypeptides and the 'Ubiquitin C-terminal hydrolase' or UCH-domain. In black are amino acids that are identical in all polypeptides; in grey are amino acids that are identical to two or three polypeptides. The differences with the normal sequence are indicated with an arrow.

found at positions 122 and 123, and three in the altered sequence. In mice and rats, this threonine residue is not present. The substitution $494 \mathrm{~T}>\mathrm{C}$ causes the change of a leucine into a serine, which is already present in the protein sequence from $M$. musculus and $R$. norvegicus. The third modification causes the substitution of a large, aromatic and polar histidine into a small and slightly polar serine. This modification is located in the 'Ubiquitin C-terminal hydrolase' or UCH-domain (Genbank: KOG1868). This histidine is present neither in this domain nor in the amino acid sequence of the USP26 gene from $M$. musculus and $R$. norvegicus.

The presence of USP26 RNA in testis was confirmed by performing RT-PCR on RNA isolated from testicular tissue. The expression of USP26 RNA in ovaries has also been analysed. These results showed that no RNA from the USP26 gene was present in ovarian tissue. As a positive control, RNA from DAZLA was amplified from ovarian tissue.

\section{Discussion}

In this study, we have screened the USP26 gene for mutations in patients with a complete and incomplete SCOS. This gene was first identified in spermatogonia of mice. ${ }^{4}$ Wang et al have found that the human homologue of USP26 shows a testis-specific expression pattern. By performing RT-PCR, we have confirmed the presence of USP26 in testicular tissue and its absence in ovarian tissue. In mice, the gene was isolated from spermatogonia, but other cell types have not been investigated. However, in humans, it is not known at which stage of spermatogenesis USP26 mRNA is present.

USP26 contains a conserved ubiquitin C-terminal hydrolase domain and is therefore probably involved in the regulation of protein turnover. In reviews, the presence and importance of ubiquitin and the ubiquitin pathway during gametogenesis was described, especially in the replacement of histones by protamines. ${ }^{5,6,7}$ Another ubiquitin-specific protease gene involved in spermatogenesis is USP9Y. Brown et $a l^{8}$ showed that Dffry, the mouse homologue of USP9Y, is expressed in the gametes. The USP9Y gene is located in the AZFa region of the $\mathrm{Y}$ chromosome. Its absence is often associated with an early blockage of spermatogonial proliferation, eventually causing SCOS in adults. Since mouse Usp26 was also found to be expressed in spermatogonia, mutations in this gene might also lead to SCOS.

We have analysed the USP26 gene of 111 patients featuring an idiopathic nonobstructive azoospermia and SCOS on a testicular biopsy. All patients had a normal karyotype. In testicular tissues of 23 patients, a few sperm cells were found (iSCOS). Interestingly, we have found eight patients with exactly the same three changes in the nucleotide sequence of the USP26 gene. Among these patients were one man with a varicocoele and one man with a Yq11 microdeletion. So the frequency of alterations in the group of men with SCOS was $7.2 \%$. Two substitutions, $494 \mathrm{~T}>\mathrm{C}$ and $1423 \mathrm{C}>\mathrm{T}$ cause the alteration of a leucine into a serine and a histidine into a tyrosine respectively; the insert of ACA causes the insert of a threonine. The consequence of these three alterations at the functional level is unclear.

Furthermore, a total of 32 patients with MA and 152 control samples or $210 \mathrm{X}$ chromosomes have been analysed. The alterations of the DNA sequence of the USP26 gene described in this paper have not been observed in patients with MA or in control samples.

Five of the eight patients with the alterations were of Arabic origin (from the Middle East), two were Caucasians and the ethnic origin of the last patient was unknown. These patients were not genetically related. The control group also included individuals of different ethnic origins; $\sim 9 \%$ were of Arabic origin.

Given the relatively high frequency of alterations in the group with SCOS and the absence of alterations in the control group, an association with infertility is possible. De 
novo mutations may be excluded since it seems highly unlikely that exactly the same two nucleotides have been changed and that the same three nucleotides have been inserted at the same position. If these mutations are disease-causing elements, the disease is likely to show an $\mathrm{X}$-linked recessive inheritance pattern. Unfortunately, because the parents or other male or female relatives of seven patients were living outside Belgium, they were not available for analysis. The last patient was lost for followup. Another possibility is that these changes do not directly affect infertility, but are a risk factor for male infertility, maybe by acting together with fertility factors not identified yet. In agreement with the latter, we have found one patient with the three alterations and a Yq microdeletion. On the contrary, these results might partly explain the variable phenotype of patients with Yq microdeletions. The reason why the seminal patterns or histological observations of patients with seemingly identical deletions of the long arm of the Y chromosome differ so much is still unclear. Finally, we cannot completely exclude that the alterations represent a polymorphism.

Testicular tissues from the eight patients with the possible mutations were not available to analyse whether some expression of USP26 mRNA still might be observed.

Further research is necessary to investigate the function of the normal and altered USP26 gene in male infertility. Furthermore, identification and clinical characterization of other patients and male relatives with the possible mutations will bring more insight into the importance of these changes.

\section{Acknowledgements}

We thank the laboratory, clinical and paramedical staff of the centers for Medical Genetics, Reproductive Medicine and the Department of Pathology for their assistance. We also specially thank Deborah Vandermaelen and Bart Saerens for their practical support. We also thank Michael Withburn of the Language Education Center and Anneleen De Coux for proofreading the manuscript. The work was supported by grants from the Fund for Scientific Research (FWOVlaanderen), and from the Research Council and a Concerted Action of the Free University of Brussels (Vrije Universiteit Brussel).

\section{References}

1 Greenhall E, Vessey M: The prevalence of subfertility: a review of the current confusion and a report of two new studies. Fertil Steril 1990; 54: 978-983.

2 Iammarrone E, Balet R, Lower AM et al: Male infertility. Best Pract Res Clin Obstet Gynaecol 2003; 17: 211-229.

3 Escalier D: Impact of genetic engineering on the understanding of spermatogenesis. Hum Reprod Update 2001; 7: 191-210.

4 Wang PJ, McCarrey JR, Yang F et al: An abundance of X-linked genes expressed in spermatogonia. Nat Genet 2001; 27: 422-426.

5 Baarends WM, Roest HP, Grootegoed JA: The ubiquitin system in gametogenesis. Mol Cell Endocrinol 1999; 151: 5-16.

6 Baarends WM, van der Laan R, Grootegoed JA: Specific aspects of the ubiquitin system in spermatogenesis. J Endocrinol Invest 2000; 23: 597-604.

7 Bebington C, Doherty FJ, Fleming SD: The possible biological and reproductive functions of ubiquitin. Hum Reprod Update 2001; 7: $102-111$.

8 Brown GM, Furlong RA, Sargent CA et al: Characterisation of the coding sequence and fine mapping of the human DRRFY gene and comparative expression analysis and mapping to the Sxrb interval of the mouse Y chromosome of the Dffry gene. Hum Mol Genet 1998; 7: 97-107. 